From the American

Board of Family Medicine

Ann Fam Med 2014;81-83. doi: 10.1370/afm.1609.

\section{PISACANO LEADERSHIP FOUNDATION NAMES 2013 PISACANO SCHOLARS}

The Pisacano Leadership Foundation, the philanthropic arm of the American Board of Family Medicine (ABFM), recently selected its 2013 Pisacano Scholars. These 6 medical students follow in the footsteps of 91 scholar alumni who are practicing physicians and 15 current scholars who are enrolled in medical schools in family medicine residency programs across the country. The Pisacano Leadership Foundation was created in 1990 by the ABFM in tribute to its founder and first executive director, Nicholas J. Pisacano, MD. Each Pisacano Scholar has demonstrated the highest level of leadership, academic achievement, communication skills, community service, and character and integrity.

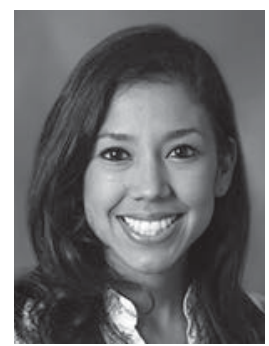

Brenda Campos-Spitze, a 2013 Pisacano Scholar, is a 4 th-year medical student at the University of California (UC), Irvine School of Medicine. She graduated from UC, Davis with a Bachelor of Science in Biological Sciences. Brenda completed her Master in Public Health at Johns Hopkins Bloomberg School of Public Health, where she received the Reed-Frost Scholarship, a full-tuition, merit-based scholarship given in recognition of her outstanding work and future potential in public health.

As an undergraduate, Brenda was a member of the National Society of Collegiate Scholars. She served as a Spanish translator, and as an employee of the Manor College Office of Continuing Education she created and taught a Spanish class to medical professionals.

Brenda worked previously as a medical assistant to family and served as a medical student volunteer on several trips to Valle Redondo, Mexico and for 2 months at a clinic in a rural village of Kenya. She is the co-chair of the Referrals Committee for the UC-Irvine Outreach Clinic (UCIOC). UCIOC is dedicated to improving the health of the mostly Spanish-speaking uninsured population in Orange County.

Brenda points to her experience working with the low-income community of Duroville as her most rewarding leadership experience. As part of the Duroville Project, she helped formulate a Community Needs Assessment that resulted in over $\$ 200,000$ in grant funds to support health programs and renovate the park's community center. The grants also paid for 5 Duroville women to be trained as health promoters for new diabetes and children's health programs.

As a family physician, Brenda plans to practice patient-centered primary care among California's growing Latino immigrant population. Furthermore, she looks forward to becoming a leader in diabetes and obesity prevention through her work in food and nutrition policy.

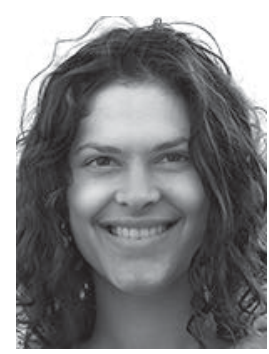

Anastasia Coutinho, a 2013 Pisacano Scholar, is a 4 th-year medical student at the University of Vermont College of Medicine. She graduated from McGill University in Montreal, Quebec with a Bachelor of Science in Physiology and completed her Master in Health Sciences in International Health at Johns Hopkins Bloomberg School of Public Health.

At McGill, Anastasia received the Alvin Shrier Scholarship and an Undergraduate Research Award from the Natural Sciences and Engineering Research Council of Canada.

While at Johns Hopkins, Anastasia worked as a research assistant and completed her Master's thesis in Bangladesh, where she developed and led a qualitative study consisting of interviews with ethnic minorities in rural Bangladesh regarding pregnancy-related care, including malaria prevention and treatment.

As a medical student, Anastasia has received numerous awards and scholarships. As a second-year medical student, Anastasia began the development and implementation of a student-faculty collaborative clinic for underserved patients. Anastasia continues toward the establishment of the Health Umbrella of Burlington, which will consist of community health teams including students from multiple health sciences. She has served as a co-leader of the Health Policy Interest Group at the UVM College of Medicine and as President of the American Medical Women's Association UVM Chapter.

Currently, Anastasia is working with the Johns Hopkins University Institute of International Programs on a large-scale evaluation of a child health program in Burkina Faso, West Africa. Anastasia is passionate about the integration of family medicine and public health within the context of domestic underserved and global settings. 


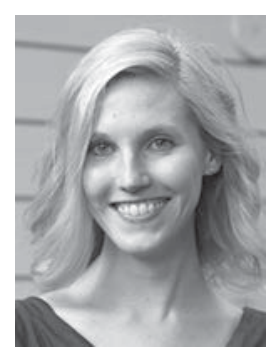

Glenna Martin, a 2013 Pisacano

Scholar, is a 4th-year medical student at the University of Washington School of Medicine (UW), where she also completed her Master in Public Health. She graduated from Skidmore with a Bachelor of Arts in Biology. At Skidmore, Glenna was elected to Phi Beta Kappa and received the Thoroughbred Award for Excellence in Leadership. Glenna also volunteered with numerous organizations.

Following graduation, Glenna spent the summer in Costa Rica with 2 local health clinics assisting in various medical duties, helping organize and carry out activities for children, and designing a public health project investigating the sexual health knowledge of women.

Glenna has received numerous awards, and last year was co-leader of The Differential, a student-led, case-based teaching session for 1st- and 2nd-year medical students. Glenna is a member of a student group that addresses health disparities, and the UW Curriculum Renewal Committee on Health Equity, and she co-chairs the Washington State Medical Association Health Equity Task Force. She also helped organize Sexpertise Week, which promotes a more positive, open, healthy and safe sex culture.

Glenna is participating in UW's Underserved Pathway, Hispanic Health Pathway, as well as the Global Health Pathway. Glenna received the UW School of Medicine Service Award in 2011, 2012, and 2013 and the SPARX/CHAP Award for outstanding volunteer activities in 2010.

Glenna is thrilled to continue pursuing her dream of becoming a family doctor in an underserved area working as part of a team. In and out of the clinic, she also hopes to participate in community activism, public health promotion, medical education, human rights work, and the conscious, conscientious use of health to promote human dignity and social justice.

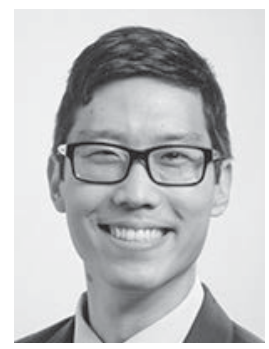

Brian Park, a 2013 Pisacano Scholar, is a 4 th-year medical student at the University of Minnesota Medical School. He graduated Cum Laude from the University of Minnesota - Twin Cities with a Bachelor of Arts in Psychology and completed his Master of Public Health at the University of Minnesota School of Public Health. Each year as an undergraduate, Brian was named to the Dean's List and received the President's Distinguished Student Scholar
Award. Brian also worked as a research assistant and was involved in several research trials and also helped develop the electronic Primary Care Research Network.

Brian previously worked for the Naomi Berrie Diabetes Center at Columbia University, partnering with urban underserved communities. Brian focused his community service projects on advocating for lowincome populations. He partnered with local organizations to rally against a proposal to cut the safety-net health insurance for the state's most impoverished citizens. Brian received an Arnold P. Gold research fellowship to help develop homeless respite care facilities in Minneapolis.

Brian was 1 of 2 students selected to participate in the Metropolitan Physician Associate Program (MetroPAP). He used his MetroPAP experience to develop academic and community service projects. The experience led him to create and host The Waiting Room, a recurring, live medical storytelling event. Brian has received numerous awards, including the Leonard Tow Humanism in Medicine Award and the Mary A. McEvoy Award for Public Engagement and Leadership. He was also inducted into the Gold Humanism Honor Society.

Following residency, Brian plans to remain in academic Family Medicine and practice in the urban underserved area. He hopes to creatively engage future generations of Family Medicine leaders in public health, legislative advocacy, health care systems transformation, and medical humanities.

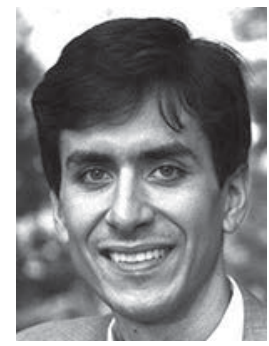

Max Romano, a 2013 Pisacano Scholar, is a 4th-year medical student at Johns Hopkins University School of Medicine, and he is also completing his Master in Public Health at Johns Hopkins Bloomberg School of Public Health. He graduated with honors from Stanford University with a Bachelor of Arts in Human Biology. At Stanford, Max was a Gold Medal Recipient of the Congressional Award for Youth in Public Service for completing over 1,700 hours of community service.

Max interned in 2 nonprofit international health clinics in the Bay Islands of Honduras. He served as a National Health Policy Intern with the National Hispanic Medical Association. He published his undergraduate thesis project in the Archives of Internal Medicine, examining the effects of certain types of electronic health records on the quality of primary care nationwide.

At Johns Hopkins, Max interned with the Center to Eliminate Cardiovascular Health Disparities, researching cultural perceptions of health disparities within an urban academic primary care network. 
Max has been a member of the Governing Board of the Student Outreach Resource Center (SOURCE) at Johns Hopkins for 3 years. He is a co-leader of his medical school's Urban Health Interest Group and Family Medicine Interest Group, he sat on the board of the Maryland Academy of Family Physicians Foundation, and he served as a Student Delegate to the National Congress of Student Members of the American Academy of Family Physicians (AAFP). Recently, Max was appointed to a 1-year term on the AAFP's Commission on Health of the Public and Science and was named a Sommer Scholar at the Johns Hopkins Bloomberg School of Public Health.

As a future family physician, Max looks forward to practicing community-based primary care and preventive medicine. He wants to bring innovative models of primary care delivery to underserved communities and provide coordinated, comprehensive, and compassionate care to his patients.

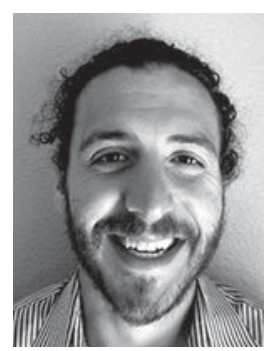

Chas Salmen, a 2013 Pisacano Scholar, is a 4th-year medical student at the University of California, San Francisco School of Medicine (UCSF). He graduated with honors from Duke University with a Bachelor of Arts in English Literature. He was awarded a Rhodes Scholarship where he was awarded highest distinction upon receiving his Master in Medical Anthropology.

At Duke, Chas was captain of the varsity cross country and track and field teams. Chas was also the founder and chairman of Peace or Pieces, an Arab-Jewish Student Coalition that raised over $\$ 20,000$ for twin communities in Southern Lebanon and Northern Israel.

Chas is the founding director of The Organic Health Response (OHR) in Kenya. Today, OHR has an annual budget of over $\$ 250,000$ per year and is a US-based 501c3 nonprofit and a registered Community-Based Organization in Kenya. Chas directs a team of 12 USbased staff and volunteers and 42 full-time Kenyan staff

As a medical student, Chas was awarded the UCSF School of Medicine Dean's Yearlong Research Fellowship. He is the senior vice-president of MicroClinic International (MCI), a global nonprofit with programs in Jordan, India and Appalachia-USA. Chas secured a $\$ 100,000$ catalyst grant to launch the world's first MicroClinic program for HIV/AIDS on Mfangano Island.

Chas looks forward to continuing his clinical training as a rural family physician. Eventually, he hopes to build a community-based practice in the rural Midwest while continuing to grow clinical services on Mfangano Island, Kenya.
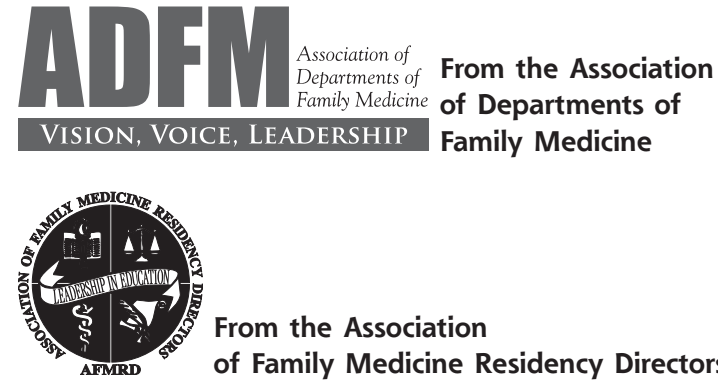

From the Association of Family Medicine Residency Directors
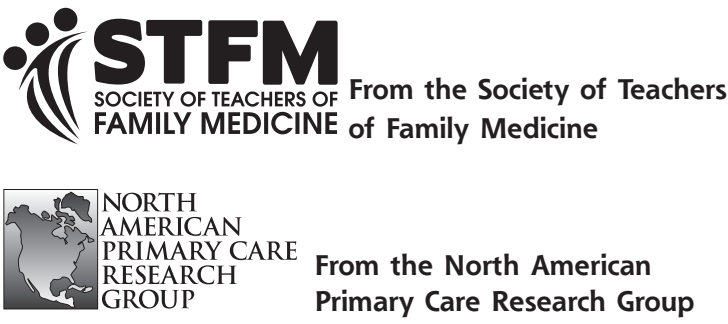

Ann Fam Med 2014;83-87. doi: 10.1370/afm.1608.

\section{THE FOUR PILLARS FOR PRIMARY CARE PHYSICIAN WORKFORCE REFORM: A BLUEPRINT FOR FUTURE ACTIVITY}

The passage of the Affordable Care Act and the introduction of health insurance exchanges are increasing demand for a primary care physician workforce able to manage populations, deliver care within inter-professional teams, and address quality outcomes of practice. Nevertheless, national statistics demonstrate that an insufficient number of students and residents are choosing primary care careers. ${ }^{1-5}$ Family medicine organizations and researchers have identified factors that influence specialty choice including individual learner characteristics, training and practice environments, and payment systems, ${ }^{6-11}$ and national debates continue the conversation about physician workforce. ${ }^{12}$ This paper presents a framework with consistent language to guide our efforts to increase production of well-trained primary care physicians for our populations.

The Council of Academic Family Medicine (CAFM), representing the family medicine academic organizations, has adopted the "Four Pillars for Primary Care Physician Workforce" as a succinct model to identify necessary conditions to ensure the needed growth in the number of primary care physicians. We are very pleased that other family medicine organizations, including the American Academy of Family Physicians (AAFP), the American Board of Family Medicine (ABFM), and the AAFP Foundation have joined CAFM in embracing this model and language as a blueprint for growing the number of primary care physicians. We expect that this conceptualization 